\title{
Analyse comparée de la structure des exploitations oléicoles européennes
}

Oléagineux, Corps Gras, Lipides. Volume 11, Numéro 3, 208-9, MAI-JUIN 2004, UE : le projet de réforme de l'OCM

Auteur(s) : Jean-Luc GURTLER

ONIC-ONIOL

21, Avenue Bosquet 75341 Paris cedex 07

\section{ARTICLE}

Le secteur oléicole européen présente une diversité tant sur le plan de la structure des exploitations que de l'organisation des filières régionales qui rend improbable la définition d'un profil européen type de l'exploitation oléicole. Cette diversité est sûrement sa richesse, mais peut également représenter une difficulté pour en appréhender la réalité économique et concevoir une OCM adaptée à toutes les régions de production.

\section{Un nombre élevé de producteurs sur des petites exploitations}

D'après les chiffres fournis par la Commission établis à partir des déclarations annuelles de culture, il y aurait 2,45 millions d'oléiculteurs dans la communauté. Ce chiffre serait bien sûr supérieur si nous considérions les personnes vivant de l'oléiculture.

C'est en Italie que les producteurs sont les plus nombreux (1 100000$)$, puis en Grèce (520 000). L'Espagne n'arrive qu'en troisième position avec 450000 oléiculteurs, alors qu'elle produit plus de $50 \%$ de l'huile communautaire. Le Portugal et la France se positionnent en queue de peloton avec respectivement 110000 et 25000 agriculteurs.

Les exploitations oléicoles sont le plus souvent de petite dimension, notamment en Italie et en Grèce où elles ne dépassent pas les 2 hectares. Elles atteignent en moyenne 6,1 hectares et 5,6 hectares en Espagne et au Portugal. A côté de ces petites structures de production, existent quelques grandes exploitations dites "professionnelles » $»^{\frac{1}{4}}$ qui présentent des superficies plus grandes $(13,5$ ha pour I'Espagne, 9,4 ha pour le Portugal, 3,2 ha pour la Grèce et 4 ha pour l'Italie). Néanmoins, ces unités restent encore très inférieures à la superficie nationale moyenne des exploitations agricoles ${ }^{\underline{2}}$ et se concentrent sur quelques régions européennes.

C'est en Italie et en France que l'on trouve les plus fortes proportions de toutes petites exploitations en termes de nombre d'arbres. D'après les déclarations de culture, 36,9\% des exploitations en Italie et $45,2 \%$ en France comptent moins de 50 arbres, alors que ce pourcentage se réduit à $17 \%$ en Espagne, Grèce et Portugal.

La taille réduite des exploitations ne permet pas de vivre facilement de l'activité oléicole et explique la proportion importante de producteurs à temps partiel parmi les oléiculteurs européens. 


\section{Des performances économiques très différentes selon les régions européennes}

La rentabilité des exploitations dépend d'un nombre élevé de facteurs : rendement, nombre d'actifs, dimension des exploitations, prix de vente.

Les performances économiques sont très variables. Ainsi, les données du RICA indiquent que la valeur ajoutée brute par hectare peut varier dans la communauté de 1 à 6 en fonction des prix et des rendements. Elle est faible au Portugal, moyenne en Espagne et forte en Italie et en Grèce. En revanche, compte tenu de la forte productivité du travail en Espagne (un actif cultive 19,5 ha dans ce pays, contre 5,5 en Italie et 2,1 en Grèce), la hiérarchie se trouve être inversée pour le revenu par actif (tableau 1).

Par rapport aux autres productions agricoles, les résultats du RICA indiquent qu'en Espagne le revenu par actif familial en oléiculture est supérieur à ceux des autres productions végétales et dépasse même de 20 \% la moyenne des autres orientations agricoles confondues. En Italie, le revenu par actif familial en oléiculture est supérieur à ceux des cultures arables, mais se situe en retrait de $4 \%$ de la moyenne de toutes les orientations agricoles confondues. En Grèce, le revenu par hectare est inférieur de $10 \%$ à la moyenne, alors qu'au Portugal le revenu de l'oléiculture est équivalent au revenu procuré par la moyenne de l'ensemble des orientations agricoles (tableau 2 ). Tableau 1. Valeur ajoutée brute sur la période 1995-1999 (Euros).

\begin{tabular}{|l|l|l|l|l|}
\hline & Italie & Grèce & Espagne & Portugal \\
\hline \hline VA/ha & $2090 / 3640$ & $2620 / 2870$ & $1230 / 1860$ & $240 / 630$ \\
\hline VA/actif & $8450 / 11700$ & $5890 / 4730$ & $8555 / 16964$ & $3000 / 7500$ \\
\hline
\end{tabular}

Tableau 2. Revenu agricole par actif familial et par orientation (période 1995-1999) (Euros).

\begin{tabular}{|l|l|l|l|l|}
\hline & Espagne & Italie & Grèce & Portugal \\
\hline Oléiculture & 20062 & 11728 & 5075 & 2775 \\
\hline \hline Céréales & 19231 & 8875 & 3418 & 7002 \\
\hline Polyculture & 18042 & 9589 & 5220 & 2078 \\
\hline Horticulture & 19035 & 16481 & 7558 & 3725 \\
\hline Vigne & 15125 & 14254 & 7520 & 3222 \\
\hline Fruits & 16351 & 10805 & 5596 & 3624 \\
\hline Lait & 12153 & 23123 & 6920 & 2126 \\
\hline Toutes orientations & 16908 & 12216 & 5699 & 2788 \\
\hline \hline
\end{tabular}




\section{Une hétérogénéité qui caractérise également l’aval de la production}

La participation des oléiculteurs à la commercialisation de l'huile d'olive présente des différences significatives entre les Etats membres. En Espagne, les oléiculteurs vendent les olives aux moulins (coopérative dans $75 \%$ des cas), qui s'occupent de la commercialisation de l'huile d'olive après son obtention. En Italie et en Grèce, le moulin se limite le plus souvent à un rôle de prestataire de service pour le compte de l'oléiculteur qui se charge ensuite de la commercialisation de son huile.

La fragmentation caractérisant le secteur oléicole concerne aussi la transformation qui comptabilise environ 11000 moulins pour l'ensemble de la Communauté. L'Italie compte à elle seule 6000 moulins et la Grèce 2 200. En Espagne, les moulins sont moins nombreux (1 700) mais d'une plus grande capacité de trituration.

La fragmentation du secteur oléicole se retrouve également au stade des installations de conditionnement soutenue par le développement des parts de marché de l'huile " extra vierge ». Cette segmentation du marché, qui représentait traditionnellement la spécificité française, est maintenant une évolution qui concerne toute l'Union européenne. Pour mieux profiter de cette évolution, les moulins intègrent de plus en plus cette étape d'aval, d'autant plus que les investissements nécessaires restent relativement modestes. En revanche, le nombre des opérateurs au stade du raffinage reste limité du fait du caractère industriel de cette activité (tableau 3).

Tableau 3. Secteur transformateur de la filière oléicole communautaire (1998-1999).

\begin{tabular}{|l|l||l|l|l|}
\hline & Espagne & Italie & Grèce & Portugal \\
\hline Moulins & 1715 & 6076 & 2232 & 929 \\
\hline Unités de raffinage & 29 & 13 & 27 & 8 \\
\hline Unités de grignon & 53 & 45 & 42 & 13 \\
\hline Unités de conditionnement & 440 & 300 & 90 & 49 \\
\hline
\end{tabular}

1 Le Réseau d'information comptable agricole (RICA) ne prend en compte que les exploitations " professionnelles » de taille suffisante pour fournir une activité principale à l'exploitant et un revenu suffisant pour subvenir aux besoins de sa famille. 2 La superficie agricole moyenne est de 29,7 ha en Espagne, 12,3 ha en Italie, 6,1 ha en Grèce et 12,2 ha au Portugal. 